\title{
Métabolisme carboné et énergétique des Pseudomonas spp fluorescents saprophytes à oxydase positive
}

\author{
X Latour, P Lemanceau* \\ Laboratoire de recherches sur la flore pathogène dans le sol, Inra-CMSE, 17, rue Sully, 21034 Dijon cedex, France
}

(Reçu le 8 juillet 1997 ; accepté le 9 janvier 1998)

\begin{abstract}
Summary - Carbon and energy metabolism of oxidase-positive saprophytic fluorescent Pseudomonas spp. Saprophytic fluorescent $P$ seudomonas spp constitute an oxidase-positive group, including the species $P$ chlororaphis, $P$ fluorescens and $P$ putida, which are common in the environment. Among these three species, some strains improve the plant growth and health and consequently are useful in agriculture. These beneficial effects are ascribed to the production of secondary metabolites (antibiotics, siderophores, phytohormones) and their synthesis is affected by the basal metabolism of the bacteria. Fluorescent pseudomonads are also implicated in the conservation of the environment. Their carbon and energy metabolism is indeed responsible for nitrate dissimilation and the degradation of xenobiotic compounds. The catabolic pathways of the main sugars, organic acids and amino acids, as well as the respiratory pathways twined to this catabolism, are presented in the present review. The use of carbohydrates is characterized by the extracellular oxidation of glucose and the prevalence of the Entner-Doudoroff pathway. The catabolism of organic and amino acids is linked to the cycles of Krebs and of the glyoxylate which play a major role in the metabolism of the bacteria. Except for arginine, the utilization of the studied compounds is only possible in the presence of oxygen or nitrogen oxides. The metabolic diversity of fluorescent Pseudomonas spp gives to these bacteria a great ability to adapt to various environments, such as the soil and the rhizosphere.
\end{abstract}

Pseudomonas chlororaphis / P fluorescens / P putida / catabolism / low molecular weight organic compounds / respiratory pathways

Résumé - Les Pseudomonas spp fluorescents saprophytes à oxydase positive, qui regroupent les espèces $P$ chlororaphis, $P$ fluorescens et $P$ putida, sont des bactéries ubiquistes. Au sein de ces trois espèces, certaines souches présentent un intérêt pour l'agriculture car elles améliorent la croissance et l'état sanitaire des plantes. Ces effets bénéfiques sont associés à la production de métabolites secondaires (antibiotiques, sidérophores, phytohormones) dont la synthèse est influencée par le métabolisme basal. Les Pseudomonas spp fluorescents jouent aussi un rôle dans la protection de l'environnement. Leur métabolisme carboné et énergétique est en effet responsable de la dissimilation des nitrates et de la dégradation de composés xénobiotiques. Dans cet article sont présentées les voies d'assimilation des principaux oses, acides organiques et acides aminés, ainsi que les voies respiratoires couplées à ce catabolisme. L'utilisation des sucres simples se caractérise par l'oxydation extracellulaire du glucose et la prédominance de la voie d'Entner-Doudoroff. Le catabolisme des acides organiques et aminés est associé aux cycles de Krebs et du glyoxylate qui jouent un rôle majeur dans le métabolisme de ces bactéries. À l'exception de l'arginine, l'assimilation des composés étudiés n'est possible qu'en conditions aérobies ou en présence d'oxydes d'azote. La variété du métabolisme des Pseudomonas spp fluores-

Article communiqué par Ed Topp (London, Canada)

* Correspondance et tirés à part

Tél : (33)0380633056; fax : (33) 0380633226 ; courriel : lemanceau@dijon.inra.fr 
cents confère à ces bactéries une plasticité importante dans leur adaptation à des environnements variés, tels que le sol et la rhizosphère.

Pseudomonas chlororaphis / P fluorescens / P putida / catabolisme / composés organiques simples / voies respiratoires

\section{INTRODUCTION}

Les Pseudomonas spp fluorescents forment un groupe appartenant au genre Pseudomonas sensu stricto (groupe ARN I sensu Palleroni). Les membres de ce groupe se caractérisent par l'aptitude à synthétiser en situation de carence en fer des sidérophores présentant un groupe chromophore jaune-vert, fluorescent sous rayonnement ultraviolet (Palleroni, 1984, 1992). Les premières études biochimiques concernant ces bactéries aérobies ont montré qu'il existe, à l'intérieur de ce groupe, des variations interspécifiques dans la structure de la chaîne respiratoire. L'étude des cytochromes respiratoires permet ainsi de distinguer d'une part $P$ aeruginosa et les espèces saprophytes, qui possèdent une cytochrome $c$ oxydase (Stanier et al, 1966), et d'autre part la plupart des espèces phytopathogènes dépourvues de cette enzyme (Lelliot et al, 1966 ; Sands et al, 1967). La présence ou non de cette enzyme clé est donc considérée comme un caractère taxinomique permettant de discriminer aisément les espèces fluorescentes étudiées. Généralement, les espèces oxydase-positive présentent un métabolisme plus varié que les espèces oxydase-négative qui sont toutes phytopathogènes (Misaghi et Grogan, 1969 ; Palleroni, 1984).

Au sein des Pseudomonas spp fluorescents, les espèces saprophytes à cytochrome oxydase positive $P$ chlororaphis, $P$ fluorescens et $P$ putida sont présentes à une densité élevée dans des environnements variés (Holloway, 1992 ; Schroth et al, 1992). Ces espèces font l'objet de nombreuses études compte tenu de leur intérêt potentiel en agriculture et pour l'environnement. Ainsi, certaines souches ont l'aptitude de stimuler la croissance et/ou d'améliorer l'état sanitaire des plantes (Lemanceau, 1992). De plus, la résistance naturelle de certains sols à diverses maladies d'origine tellurique a été associée à la présence de populations particulières de Pseudomonas spp fluorescents (Lucas et al, 1989 ; Lemanceau et Alabouvette, 1993). L'aptitude de certains isolats à dégrader des substances xénobiotiques a également retenu l'attention de différents chercheurs. Le catabolisme des xénobiotiques par les Pseudomonas spp fluorescents se caractérise en effet par la variété et la plurifonctionnalité des enzymes dégradatives. Il présente de multiples voies périphériques permettant les premières attaques d'une gamme importante de composés (Golovleva et al, 1992). Enfin, certaines populations de Pseudomonas spp fluorescents ont la possibilité de dissimiler l'azote (Gamble et al, 1977 ; Clays-Josserand et al, 1995). Cette dissimilation est plus ou moins complète selon le groupe taxinomique considéré (Matsubara et Zumft, 1982). Ces bactéries contribuent donc, de façon significative, à la réduction des nitrates et des nitrites qui constituent des polluants des nappes phréatiques.

Les différents travaux conduits sur ces effets bénéfiques indiquent clairement que les activités intéressantes des Pseudomonas spp fluorescents reposent sur la nature de leur métabolisme carboné et énergétique. Ainsi, la stimulation de croissance des plantes et l'activité antagoniste à l'encontre des agents pathogènes exercés par les Pseudomonas spp fluorescents sont liées à la synthèse de métabolites secondaires particuliers (Haas et al, 1991 ; Weller et Thomashow, 1993 ; Dowling et O'Gara, 1994). L'expression de l'ensemble de ces effets bénéfiques est d'autant plus intense que la densité bactérienne est élevée. De plus, des travaux récents réalisés sur des molécules particulières du groupe des homosérine-lactones indiquent que la synthèse de métabolites secondaires, antibiotiques en particulier, n'a lieu que si la densité bactérienne est suffisamment importante (Pierson et Wood, 1994 ; Pierson et al, 1994). Or la fréquence de division cellulaire est conditionnée par le métabolisme basal des bactéries. De façon plus spécifique, le métabolisme carboné et énergétique influence les activités particulières impliquées dans les effets bénéfiques. Ainsi, la synthèse de métabolites secondaires responsables de la stimulation de croissance et de la protection des plantes contre diverses maladies dépendent du métabolisme nutritionnel (Stephens et al, 1993 ; Voisard et al, 1994). Par ailleurs, les voies cataboliques permettant la dégradation de nombreuses substances xénobiotiques empruntent tout ou partie des voies préexistantes mises en jeu lors de l'assimilation de molécules aromatiques (Engesser et Schule, 1989 ; Golovleva et al, 1992 ; Harayama et al, 1992). Enfin, le flux d'électrons 
échangés au niveau de la chaîne respiratoire lors de la réduction des oxydes d'azote est influencé par le type de composés organiques, donneurs d'électrons, utilisé par la cellule (Beauchamp et al, 1989).

On distingue habituellement le métabolisme carboné qui conduit en particulier à la formation de coenzymes réduits à partir de substrats organiques et le métabolisme énergétique qui aboutit à la formation d'ATP à partir de molécules donneuses d'électrons. Au cours de cet article, les voies cataboliques impliquées dans l'assimilation de composés organiques simples et les voies respiratoires aérobie et anaérobie associées à l'utilisation de ces composés seront successivement présentées.

\section{CATABOLISME DES COMPOSÉS ORGANIQUES SIMPLES}

\section{Catabolisme des sucres et composés dérivés}

Le tableau I permet d'apprécier le comportement trophique des Pseudomonas spp fluorescents saprophytes vis-à-vis des principaux oligo et polysaccharides. Quasiment toutes les souches étudiées sont capables d'assimiler comme seule source de carbone les quatre sucres en $\mathrm{C}_{6}$ les plus couramment rencontrés dans la nature (D-glucose, Dfructose, D-mannose, galactose) ainsi que trois sucres en $\mathrm{C}_{5}$ (L-arabinose, ribose, $\mathrm{D}$-xylose). De la même manière, ces souches utilisent le glycérol, le gluconate et le 2-cétogluconate suivant la même voie d'assimilation que celle du glucose (Wood, 1955 ; Siegel et Phibbs, 1979). Elles utilisent aussi trois polyols (inositol, mannitol et sorbitol) dont la conformation est proche de celle des sucres en $\mathrm{C}_{6}$ cités plus haut. À l'opposé, très peu de polymères sont dégradés par ces bactéries. Seuls deux des six disaccharides testés (saccharose et tréhalose) et aucun des trisaccharides ou polysaccharides étudiés sont assimilés. L'assimilation ou non du saccharose, du tréhalose, des pentoses et des polyols par les Pseudomonas spp fluorescents saprophytes permet leur discrimination infraspécifique.

\section{Catabolisme du glucose}

Chez les Pseudomonas spp fluorescents, les premières étapes permettant l'assimilation du glucose aboutissent à la formation d'un composé clé, le 6-phosphogluconate. Plusieurs voies sont responsables de la synthèse de ce composé.
Habituellement, le glucose est oxydé en gluconate et 2-cétogluconate avant son entrée dans la cellule. Les enzymes intervenant dans ces réactions (glucose et gluconate déshydrogénases) sont des enzymes membranaires qui utilisent l'oxygène atmosphérique. Les électrons obtenus lors de l'oxydation du glucose sont transférés, via les cytochromes $b$ et $c$, à la chaîne respiratoire (Wood, 1955). L'oxydation du glucose n'est cependant pas une condition obligatoire à son transfert dans la cellule où il peut directement pénétrer grâce à une perméase (Eisenberg et al, 1974). Ce dernier système présente un intérêt particulier puisque c'est le seul qui permet l'utilisation du glucose en anaérobie sous conditions dénitrifiantes (Hunt et Phibbs, 1983). Glucose, gluconate et 2-cétogluconate cytosoliques sont ensuite phosphorylés et convertis en 6-phosphogluconate (fig 1).

Les Pseudomonas spp fluorescents ne possèderaient pas la totalité des enzymes intervenant dans la voie d'Embden-Meyerhof (ou glycolyse), ce qui expliquerait pourquoi ces microorganismes ne peuvent pas fermenter le glucose (Wood, 1955 ; De Ley, 1960). Lors d'une étude récente, Schleissner et al (1997) ont recherché certaines enzymes glycolytiques chez $P$ putida $\mathrm{U}$. Chez cette souche, les auteurs ont mis en évidence l'hexokinase qui active notamment le glucose en glucose-6-P, mais n'ont observé que des traces de la glucose-6-P isomérase qui convertit le glucose6-P en fructose-6-P. Enfin, ils n'ont pas détecté la 6-phosphofructokinase, responsable de la phosphorylation du fructose-6-P en fructose-1,6-biP. Des résultats similaires avaient déjà été observés chez $P$ aeruginosa et chez d'autres espèces de Pseudomonas (Lessie et Phibbs, 1984). Le glucose consommé par les Pseudomonas spp fluorescents est donc transformé en totalité en 6-phosphogluconate et assimilé selon les voies d'EntnerDoudoroff et du Shunt de l'hexose monophosphate (fig 1 ). D'abord décrite chez $P$ saccharophila, la voie d'Entner-Doudoroff (1952) a également été mise en évidence chez $P$ fluorescens (Wood, 1955). Elle est considérée comme la voie typique du catabolisme des sucres chez les Pseudomonas spp (Palleroni, 1984). Les enzymes caractéristiques de cette voie sont la 6-phosphodéshydratase et une aldolase qui clive le 2-céto-3-désoxy-6phosphogluconate en glyceraldéhyde-3-P et pyruvate. Le gluconate serait le principal inducteur de cette voie (Quay et al, 1972). La voie du shunt de l'hexose monophosphate emprunte le tronc commun précédemment décrit qui conduit du glucose au 6-phosphogluconate. Le 6-phosphogluconate est alors clivé en ribulose-5-P et $\mathrm{CO}_{2}$. Le cycle fait intervenir deux autres pentoses phosphatés, le D- 
Tableau I. Assimilation de 49 oses et composés dérivés comme seule source de carbone par les Pseudomonas spp fluorescents saprophytes à oxydase positive.

\begin{tabular}{|c|c|c|c|c|c|c|}
\hline & $\begin{array}{c}\text { Misaghi et Grogan } \\
\text { (1969) }\end{array}$ & $\begin{array}{l}\text { Palleroni } \\
\text { (1984) }\end{array}$ & $\begin{array}{l}\text { Digat et Gardan } \\
\quad(1987)\end{array}$ & $\begin{array}{l}\text { Rayney et al } \\
\quad \text { (1994) }\end{array}$ & $\begin{array}{l}\text { Grimont et al } \\
\quad(1996)\end{array}$ & $\begin{array}{l}\text { Latour } \\
\text { (1996) }\end{array}$ \\
\hline & \multicolumn{6}{|c|}{ Nombre de souches étudiées } \\
\hline & 32 & n.p. & 252 & 30 & 65 & 340 \\
\hline D-Glucose & +++ & + & +++ & +++ & +++ & +++ \\
\hline Gluconate & +++ & + & +++ & +++ & +++ & +++ \\
\hline 2-Cétogluconate & + & + & +++ & +++ & +++ & +++ \\
\hline 5-Cétogluconate & n.d. & n.d. & --- & + & - & + \\
\hline D-Fructose & +++ & + & +++ & +++ & +++ & +++ \\
\hline D-Mannose & + & + & +++ & +++ & + & +++ \\
\hline Galactose & + & + & +++ & +++ & + & + \\
\hline D-Arabinose & --- & -.. & --- & - & n.d. & --- \\
\hline L-Arabinose & + & + & +++ & + & + & + \\
\hline Ribose & n.d. & + & +++ & +++ & + & + \\
\hline D-Xylose & - & + & + & + & + & + \\
\hline L-Xylose & n.d. & n.d. & --- & -- & n.d. & - \\
\hline D-Lyxose & n.d. & n.d. & n.d. & + & - & + \\
\hline L-Sorbose & --- & n.d. & - & - & --- & --- \\
\hline Rhamnose & --- & - & - & - & - & --- \\
\hline D-Gentiobiose & n.d. & n.d. & --- & - & --- & --- \\
\hline D-Turanose & n.d. & n.d. & --- & - & --- & --- \\
\hline D-Tagatose & n.d. & n.d. & - & - & --- & --- \\
\hline D-Fucose & n.d. & --- & n.d. & - & n.d. & --- \\
\hline L-Fucose & --- & n.d. & --- & - & -- & --- \\
\hline Glycérol & + & +++ & +++ & +++ & +++ & +++ \\
\hline Erythritol & - & - & --- & + & + & + \\
\hline Adonitol & - & - & - & + & + & --- \\
\hline Dulcitol & --- & n.d. & - & --- & -- & -- \\
\hline D-Arabitol & - & n.d. & +++ & +++ & + & + \\
\hline L-Arabitol & - & n.d. & --- & + & + & + \\
\hline Xylitol & n.d. & n.d. & - & + & + & --- \\
\hline Inositol & + & + & n.d. & + & + & + \\
\hline Mannitol & + & + & +++ & +++ & + & + \\
\hline Sorbitol & + & + & n.d. & + & + & + \\
\hline D-Cellobiose & --- & --- & --- & - & --- & --- \\
\hline Maltose & --- & --- & -- & - & --- & --- \\
\hline Lactose & --- & --- & --- & --- & --- & --- \\
\hline D-Mélibiose & n.d. & n.d. & --- & - & --- & - \\
\hline Saccharose & + & + & n.d. & +++ & + & + \\
\hline Tréhalose & + & + & + & +++ & + & + \\
\hline D-Mélézitose & n.d. & n.d. & --- & --- & --- & -- \\
\hline D-Raffinose & --- & n.d. & -.- & + & --- & -- \\
\hline Amidon & --- & $\cdots$ & --- & + & n.d. & --- \\
\hline Glycogène & n.d. & n.d. & --- & --- & n.d. & --- \\
\hline Inuline & --- & --- & --- & - & n.d. & - \\
\hline Amygdaline & n.d. & n.d. & --- & - & n.d. & - \\
\hline Arbutine & n.d. & n.d. & --- & + & n.d. & -- \\
\hline Salicine & n.d. & n.d. & --- & $-\cdots$ & n.d. & --- \\
\hline Esculine & n.d. & n.d. & - & + & n.d. & --- \\
\hline Méthyl-D-Mannoside & n.d. & n.d. & --- & -- & n.d. & $-\cdots$ \\
\hline Méthyl-D-Glucoside & n.d. & n.d. & --- & - & --- & --- \\
\hline Méthyl-Xyloside & n.d. & n.d. & --- & - & n.d. & --- \\
\hline$N$-Acétyl-Glucosamine & n.d. & n.d. & + & +++ & + & + \\
\hline
\end{tabular}

+++ : Substrat toujours assimilé ; + : substrat fréquemment assimilé ; - : substrat rarement assimilé ; --- : substrat jamais assimilé ; np : non précisé ; nd non déterminé. 


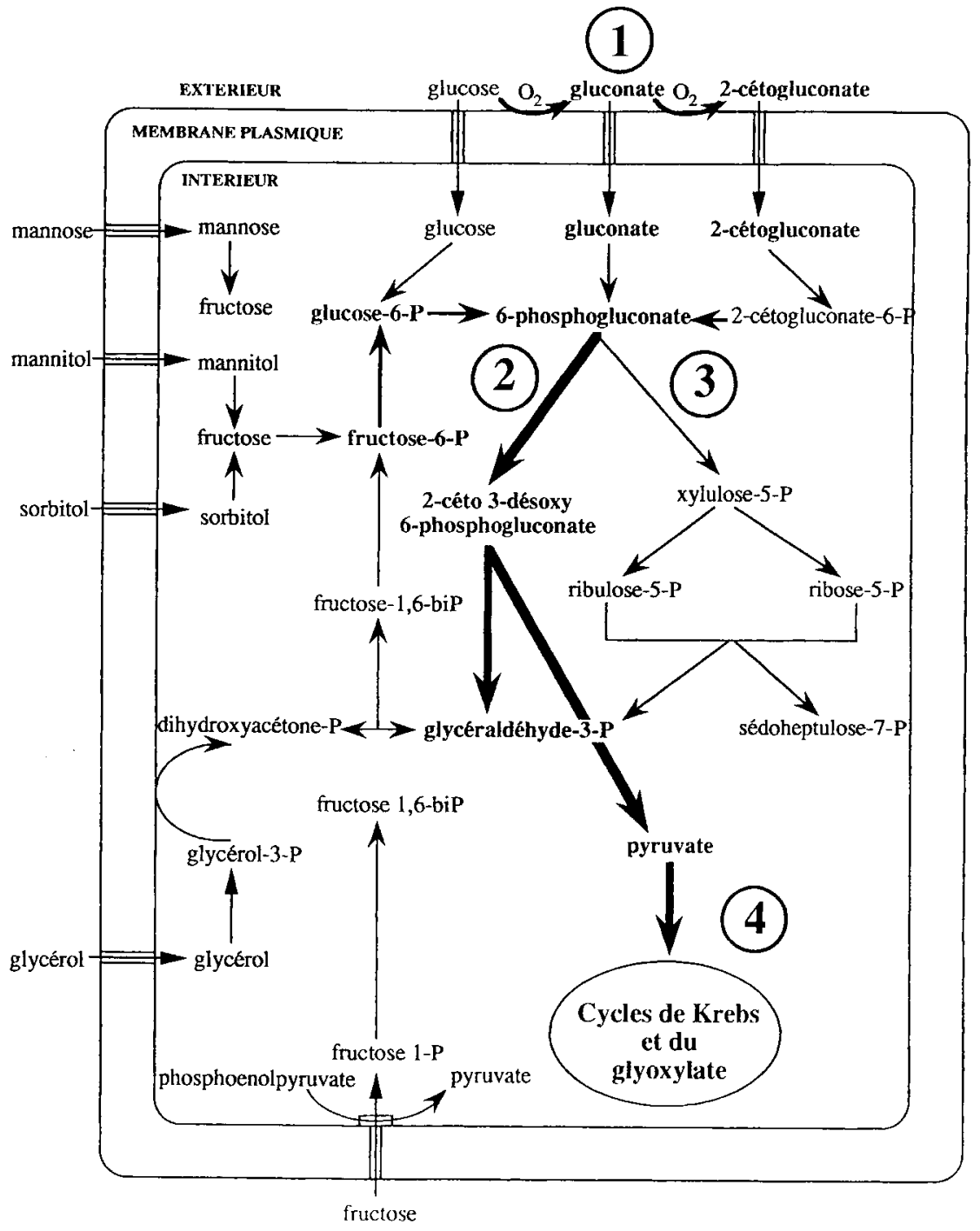

Fig 1. Catabolisme des hexoses et des polyols chez les Pseudomonas spp fluorescents saprophytes à oxydase positive. Après leur entrée dans la cellule, de nombreux hexoses et polyols sont transformés en 6-phosphogluconate. En conditions aérobies, le glucose subit généralement une oxydation préalable extracellulaire (1). Le 6-phosphogluconate synthétisé emprunte ensuite deux voies différentes : la part la plus importante (flèches en gras) est dégradée selon la voie d'Entner-Doudoroff (2), tandis qu'une petite fraction suit la voie anabolique du shunt de l'hexose monophosphate (3). L'énergie extraite de ce catabolisme provient, en grande partie, des cycles de Krebs et du glyoxylate alimentés par le pyruvate originaire de la voie d'Entner-Doudoroff (4).

ribose-5-P et le D-xylulose-5-P, d'où le nom qui lui est encore attribué : cycle des pentoses phosphates. Par ce chemin, le glucose peut être totalement oxydé en glyceraldéhyde-3-P et $3 \mathrm{CO}_{2}$ ou servir à la synthèse de différents pentoses.

La part la plus importante du glucose catabolisé le serait par la voie d'Entner-Doudoroff, en particulier lorsque le substrat est le gluconate (Quay et al, 1972 ; Eisenberg et al, 1974 ; Schleissner et al, 1997). Cependant, le rôle du shunt pourrait être beaucoup plus important chez certaines souches de $P$ fluorescens (Lewis et al, 1955). D'un point de vue énergétique, l'assimilation du glucose par l'une ou l'autre de ces voies aboutit à la formation de NADPH. Ce composé réducteur constitue un élément essentiel nécessaire pour l'organisme lors des différentes biosynthèses. À l'opposé, peu ou pas d'énergie est produite lors de l'oxydation préalable menée côté externe de la membrane plasmique. Campbell et al (1956) ont montré que durant l'oxydation du glucose en gluconate et 2 cétogluconate aucun composé phosphaté de haute énergie n'est formé, et que le rendement des cellules pour des quantités équimolaires de ces trois substrats est le même. D'après Whiting et al (1976), l'oxydation du glucose équivaudrait plutôt à sequestrer ce composé sous forme d'acides gluconiques. Cette transformation limiterait la 
consommation du glucose par les autres microorganismes et confèrerait ainsi aux Pseudomonas spp fluorescents, capables d'utiliser les formes acides, un avantage compétitif.

\section{Catabolisme des autres monosaccharides}

La voie d'assimilation du fructose utilisée par $P$ fluorescens et $P$ putida est identique à celle décrite chez $P$ aeruginosa qui constitue l'espèce type du groupe des Pseudomonas spp fluorescents. Chez ces espèces, l'entrée du fructose dans la cellule se fait par l'intermédiaire du système phosphoenolpyruvate (PEP) par lequel le fructose est activé en fructose-1-P par une phosphotransférase. Ce composé est par la suite phosphorylé une seconde fois en fructose-1,6-biP. Le fructose-1,6biP peut alors être clivé par une aldolase, mais il rejoint plus souvent la voie d'Entner-Doudoroff après formation de fructose-6-P puis glucose-6-P (Sawyer et al, 1977 ; Roehl et Phibbs, 1982). Contrairement au fructose, le mannose est un aldose. Mannose et fructose peuvent être interconvertis par une mannose isomérase (Palleroni et Doudoroff, 1956). Cette conversion permet au mannose d'emprunter la voie catabolique du fructose (fig l).

Le D-galactose, le L-arabinose et le D-xylose suivent des voies oxydatives similaires à celle d'Entner-Doudoroff pour le glucose. Dans le cas du D-galactose, la voie empruntée, appelée voie de De Ley-Doudoroff (1957), débute par l'oxydation du sucre en galactonate par la D-galactodéshydrogénase. Blachnitzky et al (1974) ont montré que chez $P$ fluorescens cette enzyme présente des propriétés particulières. Elle peut réagir à la fois avec les cofacteurs $\mathrm{NAD}^{+}$et $\mathrm{NADP}^{+}$et elle est capable d'oxyder d'autres sucres comme le Dfucose et le L-arabinose. L'assimilation du galactose mène à la formation de pyruvate et de triosesP. Celle de l'arabinose ou du xylose conduit au 2cétoglutarate (De Ley, 1960 ; Ornston, 1971).

\section{Catabolisme des polyols}

L'oxydation du mannitol et du sorbitol est associée à celle du fructose. Elle a été mise en évidence par Sebek et Randles (1952). Elle résulte de la transformation de ces composés en D-fructose grâce à des déshydrogénases dont l'action est liée au NAD ${ }^{+}$(Sebek et Randles, 1952 ; Brünker et al, 1997).

Le catabolisme du glycérol a été très étudié chez $P$ aeruginosa (Siegel et Phibbs, 1979 ; Cuskey et Phibbs, 1985 ; Schweizer et Po, 1996).
Ces études indiquent que le glycérol entre dans la cellule par diffusion facilitée. Il est alors activé par la glycérokinase avant son oxydation en dihydroxyacétone-P par une déshydrogénase membranaire. Le glycérol-3-P fournit donc directement des électrons à la chaîne respiratoire. Le dihydroxyacétone-P peut ensuite s'isomérer en glycéraldéhyde-3-P. La fusion de ces deux composés permet la formation de fructose-6-P et relie ainsi le catabolisme du glycérol à la voie d'EntnerDoudoroff (fig I).

\section{Catabolisme des disaccharides}

Le maltose, le lactose, le cellobiose et le D-melibiose ne sont pas utilisés par les Pseudomonas spp fluorescents. Seuls le saccharose et le tréhalose le sont (tableau I). Ces composés sont tous les deux dés diholosides non réducteurs ne présentant aucune mutarotation.

Le saccharose [D-glucose $1 \alpha-2 \beta$ D-fructose] est un produit important de la photosynthèse. Il représente la forme de transport de tous les glucides dans les plantes supérieures où il constitue un réservoir de glucose et fructose. De fait, c'est le photosynthétat le plus exsudé au niveau des racines (Vancura, 1988). La molécule de saccharose est par ses propriétés physicochimiques un dérivé analogue du glucose, toutefois moins réactif ; sous cette forme, le glucose demeure donc protégé de nombreuses attaques enzymatiques. Alors que l'ensemble des Pseudomonas spp fluorescents présente l'aptitude de cataboliser le glucose et le fructose, seules certaines souches sont capables d'assimiler le saccharose (tableau I). Chez les Pseudomonas spp, le saccharose subit une coupure intracellulaire par l'intermédiaire d'une phosphorylase selon la réaction : saccharose $+\mathrm{Pi} \rightarrow$ glucose-1-P + fructose (De Ley, 1960). L'assimilation du saccharose grâce à cette saccharase phosphorylase présenterait un avantage vis-à-vis de celle mettant en jeu une autre enzyme plus connue, l'invertase (saccharose $\rightarrow$ glucose + fructose). En effet, non seulement l'énergie contenue dans la liaison glycosidique est préservée, mais les réserves en ATP ne sont pas sollicitées pour activer le sucre en sucre-1-P (Gottschalk, 1979a).

Contrairement au saccharose, le tréhalose [Dglucose $1 \alpha-1 \alpha$ D-glucose] est rarement identifié chez les plantes vasculaires (Müller et al, 1995). En revanche, on le trouve dans les cellules de nombreux microorganismes. C'est un sucre caractéristique de nombreux champignons pour lesquels il représente une forme de stockage du glucose et joue le rôle d'osmorégulateur (Van Laere, 
1989). Ce double rôle est encore plus marqué chez les procaryotes comme Escherichia coli. En effet, E. coli peut utiliser le tréhalose pour ses besoins énergétiques et carbonés grâce à trois tréhalases (une périplasmique et deux cytoplasmiques) (Boos et al, 1990). Il peut également l'accumuler et le synthétiser lors de stress hyperosmotique. L'excrétion du sucre dans l'espace périplasmique, où il est dégradé, constitue alors un système de régulation intervenant lorsque le tréhalose n'est plus nécessaire (Styrvold et Strom, 1991). Le catabolisme du tréhalose semble avoir les mêmes effets chez les Pseudomonas spp fluorescents. Le tréhalose constitue en effet un soluté compatible majeur chez les Pseudomonas spp (D'Souza-Ault et al 1993 ; Miller et Wood, 1996). Ces propriétés se limitent à certaines espèces puisque le catabolisme du tréhalose est un caractère taxonomique permettant de discriminer les $P$ fluorescens et $P$ chlororaphis des $P$ putida (Palleroni, 1984).

\section{Catabolisme des acides organiques}

\section{Cycles de Krebs et du glyoxylate}

L'oxydation de nombreux acides organiques via le cycle tricarboxylique de Krebs a été principalement élucidée par Kornberg (1958) et ses collaborateurs. Elle a été observée chez toutes les espèces de Pseudomonas étudiées (Palleroni, 1984). Les résultats concernant l'assimilation des acides intervenant dans ce cycle (acétate, pyruvate, succinate, fumarate, L-malate, citrate, aconidate, 2cétoglutarate) ne sont donc pas surprenants (tableau II). Le cycle utilise la forme activée de l'acétate, l'acétyl-coenzyme A (acétylCoA) généralement produit à partir du pyruvate. Il s'amorce par la condensation de l'acétylCoA et de l'oxaloacétate permettant la formation d'un premier acide tricarboxylique, le citrate. Le citrate, sous influence de l'aconitase, se trouve ensuite en équilibre avec le cis-aconitate et l'isocitrate. L'isocitrate est converti en oxalosuccinate, avant de subir deux décarboxylations successives et une fusion avec le coenzyme A. Le cycle s'achève par la formation de plusieurs acides dicarboxyliques (succinate, fumarate, malate et oxaloacétate) (fig 2).

Kornberg et Madsen (1958) ont également découvert deux autres réactions indirectement liées au cycle de Krebs. Au cours de ces réactions, l'isocitrate peut être scindé en succinate et glyoxylate, et le glyoxylate peut fusionner avec l'acétyl$\mathrm{CoA}$ pour produire du malate. Ces réactions constituent une variante du cycle de Krebs dont le résultat est la synthèse d'acides dicarboxyliques en $\mathrm{C}_{4}$ à partir de deux molécules d'acétate. $\mathrm{Ce}$ nouveau mécanisme, appelé cycle du glyoxylate, limite la perte de carbone sous forme de $\mathrm{CO}_{2}$ lors des décarboxylations successives de l'oxalosuccinate et du 2-cétoglutarate (fig 2).

Les Pseudomonas spp fluorescents utilisent préférentiellement les acides organiques du cycle de Krebs. McGregor et al (1992) ont montré chez $P$ aeruginosa l'inhibition des voies d'assimilation de substrats comme le glucose, le fructose, le glycérol, le gluconate ou le DL glycérate. Cette répression s'observe immédiatement après l'addition dans le milieu de culture d'un acide organique tel que l'acétate, le succinate, le malate, le citrate, le fumarate ou le 2-cétoglutarate. Elle dure aussi longtemps que le composé ajouté est présent dans le milieu. Cette répression a également été observée pour d'autres composés comme l'histidine (Phillips et Mulfinger, 1981) et il est probable qu'elle s'étende à d'autres voies qui n'ont pas encore été étudiées.

\section{Catabolisme des acides gras}

Les acides carboxyliques à longue chaîne saturée, appartenant à la série $\mathrm{C}_{6}-\mathrm{C}_{10}$ (caproate, heptanoate, caprylate, pelargonate, caprate) sont fréquemment assimilés par les Pseudomonas spp fluorescents (tableau II). Les Pseudomonas spp, comme de nombreux autres microorganismes aérobies, dégradent ces acides par $\beta$ oxydation (Gottschalk, 1979b). Au cours de cette réaction, l'acide gras est d'abord converti en acylCoA-ester par une acylCoA-synthétase peu spécifique. Le CoA-ester est ensuite oxydé en position $\beta$ puis clivé pour donner de l'acétylCoA. La réaction se poursuit de façon identique avec le résidu CoA-ester jusqu'à la transformation complète en acétyl-CoA et parfois propionyl-CoA selon le nombre d'atome de carbone de l'acide.

\section{Catabolisme des acides dicarboxyliques}

L'oxydation d'acides dicarboxyliques différents de ceux présents dans le cycle de Krebs a également été décrite chez $P$ fluorescens. C'est le cas du malonate (Wolfe et al, 1954a, b et c), du glutarate (Numa et al, 1964) et de l'itaconate (Cooper et Kornberg, 1964). L'oxydation de ces acides aboutit à chaque fois à la formation d'acétylCoA et de $\mathrm{CO}_{2}$. Les acides dicarboxyliques à longue chaîne carbonée (adipate, pimélate, subérate, azélate, sébacate) ne permettent pas, par contre, la croissance des Pseudomonas spp fluorescents 
Tableau II. Assimilation de 49 acides organiques comme seule source de carbone par les Pseudomonas spp fluorescents saprophytes à oxydase positive.

\begin{tabular}{|c|c|c|c|c|c|c|}
\hline & $\begin{array}{c}\text { Misaghi et Grogan } \\
\text { (1969) }\end{array}$ & $\begin{array}{l}\text { Palleroni } \\
\text { (1984) }\end{array}$ & $\begin{array}{c}\text { Digat et Gardan } \\
\text { (1987) }\end{array}$ & $\begin{array}{l}\text { Rayney et al } \\
\text { (1994) }\end{array}$ & $\begin{array}{c}\text { Grimont et al } \\
\text { (1996) }\end{array}$ & $\begin{array}{l}\text { Latour } \\
(1996)\end{array}$ \\
\hline & \multicolumn{6}{|c|}{ Nombre de souches étudiées } \\
\hline & 32 & n.p. & 252 & 30 & 65 & 340 \\
\hline Acétate & + & +++ & +++ & +++ & n.d. & +++ \\
\hline Propionate & + & + & +++ & +++ & + & + \\
\hline Butyrate & n.d. & + & + & + & n.d. & + \\
\hline Isobutyrate & - & + & + & +++ & n.d. & +++ \\
\hline n Valérate & n.d. & + & + & + & n.d. & + \\
\hline Isovalérate & + & + & +++ & + & n.d. & + \\
\hline n Caproate & + & + & +++ & t+t & n.d. & + \\
\hline Heptanoate & + & +++ & +++ & +++ & n.d. & +++ \\
\hline Caprylate & + & +++ & +++ & +++ & +++ & +++ \\
\hline Pelargonate & + & +++ & +++ & +++ & n.d. & + \\
\hline Caprate & + & +++ & +++ & +++ & +++ & +++ \\
\hline Oxalate & - & --- & --- & --- & n.d. & --- \\
\hline Maléate & - & --- & --- & + & n.d. & +++ \\
\hline Pyruvate & +++ & +++ & +++ & +++ & n.d. & +++ \\
\hline Succinate & +++ & +++ & +++ & +++ & +++ & +++ \\
\hline Fumarate & +++ & +++ & +++ & +++ & +++ & +++ \\
\hline L-Malate & +++ & +++ & +++ & +++ & +++ & +++ \\
\hline D-Malate & + & + & + & + & + & + \\
\hline Citrate & + & +++ & +++ & +++ & +++ & +++ \\
\hline Aconitate & - & +++ & + & +++ & +++ & +++ \\
\hline 2-Cétoglutarate & +++ & +++ & - & + & + & + \\
\hline Adipate & - & - & - & --- & n.d. & + \\
\hline Pimélate & --- & - & --- & --- & n.d. & --- \\
\hline Subérate & - & - & --- & --- & n.d. & --- \\
\hline Azélate & - & - & --- & --- & n.d. & - \\
\hline Sébacate & n.d. & - & --- & - & n.d. & --- \\
\hline Glutarate & +++ & +++ & +++ & + & +++ & +++ \\
\hline Itaconate & n.d. & + & n.d. & --- & + & + \\
\hline Malonate & +++ & + & n.d. & + & + & + \\
\hline Glycolate & -- & - & - & --- & n.d. & --- \\
\hline DL-Lactate & + & +++ & +++ & +++ & +++ & +++ \\
\hline DL-Glycérate & n.d. & + & +++ & +++ & + & + \\
\hline DL-3-Hydroxybutyrate & +++ & +++ & +++ & +++ & +++ & +++ \\
\hline D-Tartrate & - & - & n.d. & - & - & + \\
\hline L-Tartrate & - & - & n.d. & + & + & + \\
\hline Mésotartrate & n.d. & - & n.d. & + & + & + \\
\hline Lévulinate & n.d. & + & n.d. & + & n.d. & +++ \\
\hline Citraconate & n.d. & + & n.d. & + & n.d. & + \\
\hline Mésaconate & + & + & - & - & n.d. & + \\
\hline Benzoate & n.d. & + & n.d. & + & + & + \\
\hline o-Hydroxybenzoate & - & - & - & --- & n.d. & - \\
\hline m-Hydroxybenzoate & - & - & -.- & - & - & -.- \\
\hline p-Hydroxybenzoate & + & + & +++ & + & + & + \\
\hline Phénylacétate & n.d. & + & n.d. & - & + & + \\
\hline D-Mandélate & - & - & - & - & n.d. & --- \\
\hline L-Mandélate & n.d. & - & n.d. & - & n.d. & --- \\
\hline Phthalate & --- & --- & --- & - & n.d. & --- \\
\hline Iso Phthalate & --- & --- & --- & - & n.d. & - \\
\hline Tere Phthalate & --- & --- & --- & - & n.d. & --- \\
\hline
\end{tabular}

+++ : Substrat toujours assimilé ; + : substrat fréquemment assimilé ; - : substrat rarement assimilé ; --- : substrat jamais assimilé ; np : non précisé ; nd : non déterminé. 


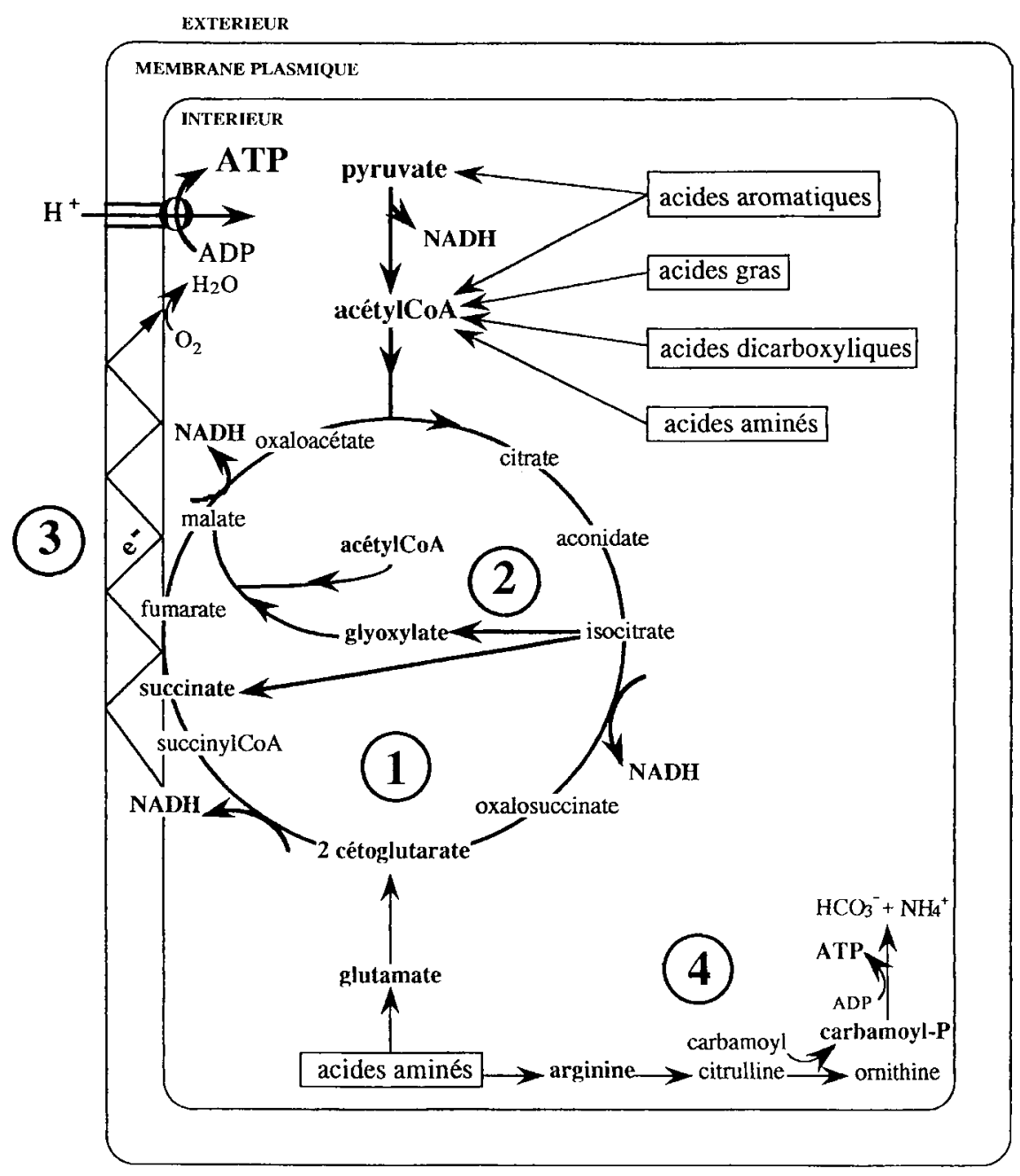

Fig 2. Catabolisme des acides organiques et des acides aminés chez les Pseudomonas spp fluorescents saprophytes à oxydase positive. Les acides organiques sont oxydés selon les réactions des cycles de Krebs (1) et du glyoxylate (2). L'extraction et le stockage de l'énergie sous forme d'ATP se fait au niveau de la chaîne respiratoire, dans laquelle les électrons sont fournis lors de la déshydrogénation du NADH et du succinate par les enzymes flaviniques membranaires (3). En anaérobiose et sous conditions non dénitrifiantes, la fermentation de l'arginine peut également produire de l'ATP (4).

croissance des Pseudomonas spp fluorescents (tableau II).

\section{Catabolisme des acides aromatiques}

De nombreux isolats de $P$ fluorescens et $P$ putida ont été cités en exemple comme souches capables de dégrader des molécules aromatiques plus ou moins complexes. Les voies permettant la dégradation de ces composés ne seront pas détaillées ici (pour revue Stanier et Ornston, 1973 ; Dagley, 1986). Il faut cependant noter que les souches étudiées ont toujours été isolées de milieux pollués par des xénobiotiques ou des hydrocarbures. L'assimilation de composés aromatiques semble par contre moins courante chez les isolats prove- nant de sols non contaminés ou de la rhizosphère (Campbell et al, 1995 ; Latour et al, 1996). Ce résultat est illustré dans le tableau $I I$ où parmi les dix acides aromatiques étudiés, seul le p-hydroxybenzoate est fréquemment assimilé et à un degré moindre le benzoate et le phénylacétate.

Bien que présentant des structures proches, le phydroxybenzoate et le benzoate sont catabolisés par des voies différentes. Le p-hydroxybenzoate est transformé en protocatechuate et le benzoate en catechol. Les cycles aromatiques de ces deux composés intermédiaires sont ensuite ouverts grâce à des dioxygénases. L'ouverture se fait généralement en ortho (1,2-dioxygénase), mais peut aussi avoir lieu en méta (2,3-dioxygénase). La voie ortho mène à la formation de succinate et d'acétylCoA, la voie méta à celle de l'acétaldéhy- 
de et du pyruvate (Stanier et Ornston, 1973 ; Harwood et al, 1984).

Le catabolisme du phénylacétate emprunterait une voie encore mal connue. L'assimilation de ce composé nécessite la participation d'un transporteur spécifique (Schleissner et al, 1994) et celle d'une enzyme particulière, la phénylacétate-CoA ligase, qui catalyse la première réaction de cette voie (Martinez-Blanco et al, 1990).

\section{Catabolisme des acides aminés}

Les Pseudomonas spp fluorescents utilisent de nombreux acides aminés comme sources de carbone, d'azote et d'énergie (Palleroni, 1984) (tableau III). L'assimilation ou non d'un nombre important de ces composés (glycine, L-tryptophane, trigonelline, L-lysine, L-citrulline,...) par les Pseudomonas spp fluorescents saprophytes permet leur discrimination infraspécifique. Les voies d'assimilation des acides aminés sont nombreuses et peuvent être illustrées à partir de quelques exemples selon que la chaîne latérale de l'acide est apolaire, aromatique ou basique.

\section{Catabolisme des acides aminés à chaîne latérale apolaire}

Les acides aminés apolaires comme la $\mathrm{D}$ et L-alanine, leucine, isoleucine et la L-valine sont quasiment toujours utilisés comme substrats carbonés par les Pseudomonas spp fluorescents étudiés (tableau III). Marshall et Sokatch (1972) puis Martin et al (1973) ont élucidé chez $P$ putida le catabolisme des formes $\mathrm{L}$ et $\mathrm{D}$ de la leucine, de l'isoleucine et de la valine. Ils montrent que ces voies mettent en jeu des enzymes communes. L'assimilation de ces acides aminés aboutit à la production d'acétoacétate, d'acétylCoA et de succinylCoA.

\section{Catabolisme des acides aminés à chaîne latérale aromatique}

Chez les Pseudomonas spp fluorescents qui peuvent utiliser ce composé, le L-tryptophane est attaqué par une $\mathrm{L}$ spécifique tryptophane-2,3-dioxygénase qui provoque la formation de formyl Lkynurénine, à son tour converti en L-kynurénine et formate. Une kynuréninase hydrolyse alors la chaîne latérale de la kynurénine libérant de l'alanine et un nouvel acide aminé aromatique, l'anthranilate (2-aminobenzoate). Ce dernier com- posé est transformé en catéchol et rejoint la voie dégradative des acides aromatiques présentée précédemment (Ornston, 1971).

La première étape de dégradation de l'histidine consiste en une désamination de l'acide aminé. L'urocanate est le premier composé intermédiaire formé, mais constitue également l'inducteur physiologique de cette voie (Hug et al, 1968 ; Newell et Lessie, 1970). Comme pour de nombreux autres acides aminés, le catabolisme de l'histidine permet la production de glutamate qui peut entrer dans le cycle de Krebs après une désamination en 2-cétoglutarate (fig 2).

\section{Catabolisme des acides aminés à chaîne latérale basique}

Le catabolisme de la lysine emprunte trois voies distinctes : la voie de l'oxygénase, celle du pipécolate et celle de la cadavérine. L'existence de ces voies dépend de l'espèce et du biovar étudiés. Les $P$ fluorescens possèderaient les trois voies, les $P$ putida du biovar A les deux premières et les $P$ putida du biovar B la seule voie du pipécolate. La L-lysine apparaît être le substrat caractéristique de la voie acyclique de l'oxygénase tandis que la D-lysine est celui de la voie cyclique passant par le pipecolate. Chacune de ces voies est spécifiquement induite par la L ou la D-lysine et leurs intermédiaires respectifs (Miller et Rodwell, 1971 ; Chang et Adams, 1971 ; Fothergill et Guest, 1977).

L'arginine représente une source d'azote intéressante dans les milieux riches en matière organique. Elle constitue une source d'énergie en aérobiose et en anaérobiose. La complexité du catabolisme de l'arginine révèle l'intérêt de ce substrat pour les microorganismes (Cunin et al, 1986). Il existe quatre voies distinctes d'assimilation de l'arginine chez $P$ putida et au moins trois d'entre elles existent chez les autres espèces de Pseudomonas spp fluorescents (Cunin et al, 1986 ; Haas et al, 1990). Ces voies mettent en jeu d'autres acides aminés comme la citrulline, l'ornithine, la proline ou le 4-aminobutyrate. Elles sont largement indépendantes les unes des autres et sont différemment utilisées selon les besoins bactériens.

La voie de l'arginine déiminase est une voie caractéristique des Pseudomonas spp fluorescents saprophytes (Thornley, 1960). Elle fonctionne seulement en absence d' $\mathrm{O}_{2}$ et sous conditions nondénitrifiantes, c'est-à-dire lorsque la chaîne respiratoire est totalement bloquée (Shoesmith et Sherris, 1960 ; Mercenier et al, 1980). C'est la 
Tableau III. Assimilation de 49 composés aminés comme seule source de carbone par les Pseudomonas spp fluorescents saprophytes à oxydase positive.

\begin{tabular}{|c|c|c|c|c|c|c|}
\hline & $\begin{array}{c}\text { Misaghi et Grogan } \\
\text { (1969) }\end{array}$ & $\begin{array}{l}\text { Palleroni } \\
\text { (1984) }\end{array}$ & $\begin{array}{l}\text { Digat et Gardan } \\
\quad(1987)\end{array}$ & $\begin{array}{l}\text { Rayney et al } \\
\quad \text { (1994) }\end{array}$ & $\begin{array}{l}\text { Grimont et al } \\
\text { (1996) }\end{array}$ & $\begin{array}{l}\text { Latour } \\
\text { (1996) }\end{array}$ \\
\hline & \multicolumn{6}{|c|}{ Nombre de souches étudiées } \\
\hline & 32 & n.p. & 252 & 30 & 65 & 340 \\
\hline Glycine & + & - & n.d. & + & n.d. & - \\
\hline D-Alanine & + & + & +++ & +++ & +++ & +++ \\
\hline L-Alanine & + & +++ & +++ & +++ & +++ & +++ \\
\hline$\beta$ Alanine & n.d. & +++ & +++ & +++ & n.d. & +++ \\
\hline L-Leucine & + & + & +++ & +++ & n.d. & + \\
\hline L-Isoleucine & + & + & +++ & +++ & n.d. & +++ \\
\hline L-Norleucine & n.d. & --- & --- & + & n.d. & - \\
\hline L-Valine & + & + & +++ & +++ & n.d. & + \\
\hline DL-Norvaline & n.d. & n.d. & --- & + & n.d. & --- \\
\hline L-Aspartate & n.d. & +++ & + & +++ & $++t$ & +++ \\
\hline L-Glutamate & + & t++ & +++ & +++ & +++ & +++ \\
\hline L-Sérine & + & + & +++ & +++ & +++ & + \\
\hline L-Thréonine & n.d. & --- & --- & + & n.d. & +++ \\
\hline L-Cystéine & n.d. & n.d. & $-\cdots$ & + & n.d. & - \\
\hline L-Méthionine & n.d. & n.d. & --- & + & n.d. & +++ \\
\hline L-Phénylalanine & + & + & +++ & +++ & n.d. & +++ \\
\hline L-Tyrosine & + & +++ & + & +++ & + & +++ \\
\hline L-Histidine & + & + & n.d. & + & +++ & +++ \\
\hline D-Tryptophane & n.d. & n.d. & --- & - & n.d. & --- \\
\hline L-Tryptophane & n.d. & + & n.d. & + & + & + \\
\hline DL-Kynurénine & n.d. & + & --- & + & n.d. & +++ \\
\hline L-Proline & + & +++ & +++ & +++ & + & +++ \\
\hline Bétaïne & + & +++ & $t+t$ & +++ & +++ & +++ \\
\hline Trigonelline & + & + & + & + & + & + \\
\hline L-Lysine & + & + & n.d. & + & n.d. & + \\
\hline L-Arginine & +++ & +++ & +++ & +++ & n.d. & +++ \\
\hline L-Citrulline & n.d. & + & n.d. & + & n.d. & + \\
\hline L-Ornithine & + & + & + & + & n.d. & + \\
\hline DL-2-Aminobutyrate & n.d. & n.d. & --- & - & n.d. & --- \\
\hline DL-3-Aminobutyrate & n.d. & n.d. & --- & + & n.d. & + \\
\hline DL-4-Aminobutyrate & n.d. & +++ & +++ & +++ & +++ & +++ \\
\hline DL-5-Aminovalérate & n.d. & + & +++ & + & + & + \\
\hline Urée & n.d. & n.d. & --- & --- & n.d. & --- \\
\hline Acétamide & - & - & --- & - & n.d. & - \\
\hline Créatine & n.d. & n.d. & --- & - & n.d. & + \\
\hline Sarcosine & + & + & +++ & +++ & n.d. & + \\
\hline Glucosamine & n.d. & n.d. & n.d. & +++ & + & + \\
\hline Ethylamine & n.d. & n.d. & --- & --- & n.d. & +++ \\
\hline Butylamine & n.d. & + & n.d. & --- & n.d. & + \\
\hline Amylamine & n.d. & + & n.d. & + & n.d. & + \\
\hline Ethanolamine & + & + & n.d. & +++ & + & + \\
\hline Benzylamine & n.d. & - & n.d. & -- & n.d. & + \\
\hline Diaminobutane & n.d. & n.d. & +++ & +++ & n.d. & +++ \\
\hline Spermine & + & +++ & +++ & + & n.d. & +++ \\
\hline Histamine & + & + & n.d. & - & + & + \\
\hline Tryptamine & $-\cdots$ & - & n.d. & + & - & + \\
\hline 2-Aminobenzoate & n.d. & n.d. & n.d. & + & n.d. & + \\
\hline 3-Aminobenzoate & n.d. & n.d. & -.. & --- & n.d. & +++ \\
\hline 4-Aminobenzoate & n.d., & n.d. & --- & --- & n.d. & +++ \\
\hline
\end{tabular}

+++ : Substrat toujours assimilé $;+$ : substrat fréquemment assimilé ; - : substrat rarement assimilé ; --- : substrat jamais assimilé ; $\mathrm{np}$ : non précisé ; nd : non déterminé. 
seule voie fermentative connue chez ces bactéries. La fonction principale de cette voie est de fournir des molécules d'ATP (une par molécule d'arginine dégradée) après régénération de l'ADP par un composé particulier, le carbamoyl-P. L'activation du carbamoyl en carbamoyl-P se produit après que l'arginine a été désaminée lors de la transformation de la citrulline en ornithine (fig 2) (Stalon et al, 1972 ; Stalon et Mercenier, 1984). Les voies de l'arginine oxydase (Miller et Rodwell, 1971) et de l'arginine succinyltransférase ou cycle de la succinylarginine (Stalon et al, 1987) sont impliquées dans le catabolisme aérobie carboné de l'arginine. Ces deux voies seraient essentielles pour la pleine croissance des $P$ putida lorsque l'arginine est utilisée comme seule source de carbone. La voie de l'arginine décarboxylase (Stalon et Mercenier, 1984) rejoint celle de l'arginine oxydase lors de la formation de 4-aminobutyrate. Cette voie est productrice de polyamines lorsque l'arginine est abondante.

\section{VOIES RESPIRATOIRES}

La dégradation des substrats organiques lors des réactions cataboliques ne fournit directement qu'une seule forme d'énergie : la forme chimique disponible dans 1'ATP, le phosphoénolpyruvate et quelques thioesters. Une autre forme essentielle d'énergie est la forme électrochimique, résultant d'une différence de potentiel électrique et de différences de concentrations ioniques entre les deux faces de la membrane plasmique. Ces différences proviennent de la circulation d'électrons dans la chaîne respiratoire et de l'accumulation dans le périplasme de charges positives (protons). Le gradient électrochimique obtenu permet la synthèse d'ATP via l'ATPase, l'accumulation de métabolites (diffusions facilitées et transports actifs), le mouvement (mise en rotation des flagelles), l'excrétion et la mise en place de protéines et polysaccharides de surface. Chez les Pseudomonas spp, les donneurs d'électrons sont principalement synthétisés au cours du cycle de Krebs : il s'agit en particulier du NADH, du NADPH, du $\mathrm{FADH}_{2}$ et du succinate. Comme cela a été discuté précédemment, le glycérol et le glucose peuvent également jouer ce rôle. L'accepteur final d'électrons de la chaîne respiratoire des Pseudomonas est l'oxygène atmosphérique. En anaérobiose, le nitrate et certaines de ses formes réduites peuvent intervenir dans cette chaîne.

\section{Respiration sur oxygène}

Les Pseudomonas spp sont définis comme étant des microorganismes aérobies utilisant l'oxygène comme accepteur final d'électrons (Palleroni, 1984). Cette respiration sur $\mathrm{O}_{2}$ est celle qui présente le rendement énergétique le plus important suite au potentiel rédox élevé de l'oxygène. Elle est caractérisée par des cytochromes oxydases, transporteurs d'électrons terminaux qui réagissent directement avec l'oxygène (pour revue, voir Thöny-Meyer, 1997). Les Pseudomonas spp fluorescents saprophytes possèdent tous une cytochrome oxydase $c$ présentant un pic d'absorption caractéristique à $552 / 554 \mathrm{~nm}$. Cette enzyme est mise en évidence par l'oxalate de $N, N$-diméthylparaphenylène-diainine (Lelliot et al, 1966 ; Stanier et al, 1966).

\section{Respiration sur nitrate et dénitrification dissimilatrice}

Lorsque l'oxygène n'est plus disponible en quantité suffisante, certaines espèces de Pseudomonas spp fluorescents font appel aux oxydes d'azote. La réduction des nitrates $\left(\mathrm{NO}_{3}^{-}+2 \mathrm{e}^{-}+2 \mathrm{H}^{+} \rightarrow \mathrm{NO}_{2}^{-}\right.$ $+\mathrm{H}_{2} \mathrm{O}$ ) se fait à l'intérieur de la cellule au niveau de la membrane interne grâce à la nitrate réductase. Elle est généralement inhibée en aérobiose, les électrons de la chaîne respiratoire étant alors préférentiellement orientés vers l'oxygène dont le potentiel rédox $\left(E^{\circ}=+820 \mathrm{mV}\right)$ est plus élevé que celui du nitrate $\left(E^{\circ \circ}=+420 \mathrm{mV}\right.$ ) (Tiedje, 1988). Les nitrites formés sont ensuite rejetés dans le milieu. Dans certains cas, ils interviennent euxmêmes comme accepteurs d'électrons et sont réduits en composés gazeux tels que les oxydes nitriques (NO) et nitreux $\left(\mathrm{N}_{2} \mathrm{O}\right)$ et l'azote $\left(\mathrm{N}_{2}\right)$. Il $s$ 'agit de la dénitrification dissimilatrice. La réduction de $\mathrm{NO}_{2}^{-}$, $\mathrm{NO}$ et $\mathrm{N}_{2} \mathrm{O}$ est sous le contrôle de réductases plus ou moins liées à la membrane plasmique et elle s'exprime côté périplasmique (Knowles, 1982). La respiration sur nitrates et la dénitrification présentent un rendement énergétique plus faible que la respiration sur oxygène. À titre d'exemple sont présentées ci-dessous, les quantités d'énergie produites lors de la respiration sur nitrate i), la dénitrification jusqu'à la production d'azote ii) et la respiration sur oxygène iii) d'une mole de glucose :

i) Glucose $+12 \mathrm{NO}_{3}^{-} \rightarrow 6 \mathrm{CO}_{2}+6 \mathrm{H}_{2} \mathrm{O}+12 \mathrm{NO}_{2}^{-}$ $\Delta \mathrm{G}^{\circ}=-1766 \mathrm{~kJ}$

ii) Glucose $+4,8 \mathrm{NO}_{3}^{-}+4,8 \mathrm{H}^{+} \rightarrow 6 \mathrm{CO}_{2}+2,4 \mathrm{~N}_{2}$ $+8,4 \mathrm{H}_{2} \mathrm{O}$

$\Delta \mathrm{G}^{\circ}=-2669 \mathrm{~kJ}$

iii) Glucose $+6 \mathrm{O}_{2} \rightarrow 6 \mathrm{CO}_{2}+6 \mathrm{H}_{2} \mathrm{O}$

$\Delta \mathrm{G}^{\circ}{ }^{\circ}=-2870 \mathrm{~kJ}$ 
Les capacités dénitrifiantes des Pseudomonas varient selon l'espèce et le biovar : $P$ fluorescens biovars I, V, et VI et $P$ putida peuvent uniquement réduire les nitrates, alors que $P$ chlororaphis et $P$ fluorescens biovars II, III et IV sont des germes dénitrifiants (Palleroni, 1984). Lors d'une étude où ont été comparées différentes souches de $P$ chlororaphis et $P$ fluorescens biovars II et III, Matsubara et Zumft (1982) ont montré que seules celles de $P$ fluorescens sont capables de réduire $\mathrm{N}_{2} \mathrm{O}$ et ainsi de réaliser une dénitrification complète.

\section{CONCLUSION}

Les Pseudomonas spp fluorescents à cytochrome oxydase positive sont des microorganismes hétérotrophes qui ont l'aptitude d'utiliser une gamme étendue de composés organiques. Leur métabolisme carboné et énergétique est construit autour des cycles de Krebs et du glyoxylate dans lesquels aboutissent la majorité des voies dégradatives. Ces bactéries utilisent préférentiellement les acides organiques plutôt que les oses et leurs dérivés. Ainsi, l'acétate et plusieurs intermédiaires du cycle des acides tricarboxyliques provoquent une répression des voies cataboliques de nombreux sucres (Mc Gregor et al, 1992). La plupart des acides aminés sont assimilés par les Pseudomonas spp fluorescents par des voies variées qui sont reliées au cycle de Krebs. Les produits des cycles de Krebs et du glyoxylate alimentent une chaîne respiratoire préférentiellement aérobie au rendement énergétique élevé. Selon la pression partielle en oxygène de l'environnement, la chaîne respiratoire utilise comme accepteurs d'électrons l'oxygène ou les oxydes d'azotes.

L'ensemble de ces caractéristiques métaboliques (diversité des composés organiques assimilés, possibilité d'utiliser différents accepteurs d'électrons) confère aux Pseudomonas spp fluorescents une capacité d'adaptation remarquable à des environnements variés (Palleroni, 1992 ; Jacques, 1994). Ainsi, ces bactéries présentent une fréquence élevée dans la rhizosphère. Cette fréquence s'explique par leur aptitude à dissimiler l'azote. En effet, la pression partielle en oxygène peut varier dans de fortes proportions du fait des variations d'humidité et de la consommation en oxygène due à la respiration racinaire et microbienne (Hojberg et Sorensen, 1993). Ainsi, les espèces microbiennes aérobies qui développent une respiration sur nitrate lorsqu'elles sont privées d'oxygène (Alcaligenes spp, Bacillus spp,
Pseudomonas spp) sont très représentées dans la rhizosphère (Smith et Tiedje, 1979). De même, les populations de Pseudomonas spp fluorescents les plus rencontrés dans la rhizosphère sont celles qui sont le plus aptes à dissimiler l'azote (ClaysJosserand et al, 1995).

Globalement, l'aptitude des Pseudomonas spp fluorescents à tirer parti des milieux riches en composés organiques grâce à leur métabolisme leur confère un avantage compétitif dans ces environnements. Cet avantage se traduit en particulier par leur vitesse de division cellulaire. Ainsi, les cellules de Pseudomonas spp se divisent en moyenne toutes les $5 \mathrm{~h}$ dans la rhizosphère de Pinus radiata et uniquement toutes les $77 \mathrm{~h}$ dans le sol non rhizosphérique (Bowen et Rovira, 1976). Cette différence conduit à un développement des Pseudomonas spp fluorescents significativement plus élevé dans la rhizosphère que dans le sol nu. Ces microorganismes sont donc considérés comme des rhizobactéries (Schroth et al, 1992). La rapidité de croissance des populations de Pseudomonas spp fluorescents en milieu riche en matière organique permet de compenser le handicap lié à l'absence de formes de conservation developpées par d'autres groupes bactériens tels que les Bacillus par exemple.

Au sein des populations de Pseudomonas spp fluorescents, le type de métabolisme carboné confère également un avantage compétitif à certaines souches capables d'utiliser des composés particuliers présents dans l'environnement et qui ne sont pas assimilés par d'autres souches. C'est le cas en particulier du saccharose et du tréhalose assimilés par les populations associées à la rhizosphère de la tomate mais pas à celle du lin (Lemanceau et al, 1995 ; Latour, 1996). Les populations de Pseudomonas spp fluorescents de la mycorhizosphère de pins douglas, mycorhizés par Laccaria bicolor, sont également capables d'utiliser le tréhalose contrairement à celles du sol (Frey et al, 1997). De plus, Colbert et al (1993) ont montré que l'introduction dans le sol d'un composé aromatique, peu utilisé par la microflore tellurique (salicylate), améliore la survie d'une souche de $P$ putida présentant les gènes du catabolisme de ce composé.

Le métabolisme basal conditionne à la fois la division cellulaire et le métabolisme secondaire. La nature et l'intensité de la synthèse des métabolites secondaires sont donc directement associées au métabolisme basal des cellules. Ainsi, la production de l'antibiotique 2,4-diacétylphloroglucinol par la souche de $P$ fluorescens F113 est stimulée par la présence de saccharose, fructose ou 
mannitol dans le milieu de culture. Elle est réduite au contraire en présence de glucose ou sorbose (Shanahan et al, 1992). De même, la synthèse de l'acide cyanhydrique est associée au catabolisme de la glycine (Knowles et Bunch, 1986). Or, la synthèse de ces métabolites, tout comme celle d'autres antibiotiques et d'enzymes particulières, sont impliquées dans les effets bénéfiques déterminés par les Pseudomonas spp fluorescents (Haas et al, 1991 ; Weller et Thomashow, 1993). La meilleure connaissance des caractéristiques du métabolisme carboné et énergétique devrait donc permettre d'améliorer l'efficacité des effets bénéfiques déterminés par des souches particulières. Ainsi, l'introduction de gènes codant pour la synthèse de métabolites intéressants ou pour leur dérégulation (Thomashow, 1991 ; Maurhofer et al, 1992 ; Schnider et al, 1995) devrait s'accompagner d'une augmentation du métabolisme basal des cellules modifiées afin d'éviter une réduction éventuelle des facultés adaptatives. De même, la caractérisation des composés utilisés en priorité par une souche inoculée permettrait de lui conférer un avantage compétitif grâce à l'introduction des composés correspondants (Lam et al, 1991 ; Lemanceau et al, 1995). Enfin, l'identification des voies métaboliques associées à la synthèse de métabolites secondaires et d'enzymes intéressantes permettrait de placer les souches dans un environnement favorable à leur synthèse et ainsi d'améliorer l'efficacité de ces souches.

\section{RÉFÉRENCES}

Beauchamp EG, Trevors JT, Paul JW (1989) Carbon sources for bacterial denitrification. Adv Microb Sci $10,113-142$

Blachnitsky EO, Wengenmayer F, Kurtz G (1974) Dgalactose dehydrogenase from Pseudomonas fluorescens: purification, properties and structure. Eur $J$ Biochem 47, 235-250

Boos W, Ehmann U, Forkl H, Klein W, Rimmele M, Postma P (1990) Trehalose transport and metabolism in Escherichia coli. J Bacteriol 172, 3450-3461

Bowen GD, Rovira AD (1976) Microbial colonization of plant roots. Annu Rev Phytopathol 14, 121-144

Brünker P, Altenbuchner J, Kulbe KD, Mattes R (1997) Cloning, nucleotide sequence and expression of a mannitol dehydrogenase gene from Pseudomonas fluorescens DSM 50106 in Escherichia coli. Biochimica et Biophysica Acta 1351, 157-167

Campbell JIA, Jacobsen CS, Sorensen J (1995) Species variation and plasmid incidence among fluorescent Pseudomonas strains isolated from agricultural and industrial soils. FEMS Microbiol Ecol 18, 51-62
Campbell JJR, Ramakrishnan T, Linnes AG, Eagles BA (1956) Evaluation of the energy gaines by Pseudomonas aeruginosa during the oxidation of glucose to 2-ketogluconate. Can J Microbiol 2, 304312

Chang YF, Adams E (1971) Induction of separate catabolic pathways for L-lysine and D-lysine in Pseudomonas putida. Biochem Biophys Res Comm $45,570-577$

Clays-Josserand A, Lemanceau P, Philippot L, Lensi R (1995) Influence of two plant species (flax and tomato) on the distribution of nitrogen dissimilative abilities within fluorescent Pseudomonas spp. Appl Environ Microbiol 61, 1745-1749

Colbert SF, Schroth MN, Weinhold AR, Hendson M (1993) Enhancement of population densities of Pseudomonas putida PpG7 in agricultural ecosystems by selective feeding with the carbon source salicylate. Appl Environ Microbiol 59, 2064-2070

Cooper RA, Kornberg HL (1964) The utilization of itaconate by Pseudomonas sp. Biochem J 91, 82-91

Cunin R, Glansdorff N, Piérard A, Stalon V (1986). Biosynthesis and metabolism of arginine in bacteria. Microbiol Rev 50, 314-352

Cuskey SM, Phibbs PV (1985) Chromosomal mutations affecting glycerol and glucose catabolism in Pseudomonas aeruginosa PAO. J Bacteriol 162, $872-880$

Dagley S (1986) Biochemistry of aromatic hydrocarbon degradation in Pseudomonas. In : The Bacteria (JR Sokatch, LN Ornston, eds), Academic Press, 10, 527-555

De Ley J (1960) Comparative carbohydrate metabolism and localization of enzymes in Pseudomonas and related micro-organisms. J Appl Bacteriol 23, 400441

De Ley J, Doudoroff M (1957) The metabolism of Dgalactose in Pseudomonas saccharophila. $J$ Biol Chem 213, 745-757

Digat B, Gardan L (1987) Caractérisation, variabilité et sélection des souches bénéfiques de Pseudomonas fluorescens et Pseudomonas putida. Bull OEPP 17 , 559-568

Dowling DN, O'Gara F (1994) Metabolites of Pseudomonas involved in the biocontrol of plant disease. Trends Biotechnol 12, 133-140

D'Souza-Ault M, Tombras-Smith L, Smith GM (1993) Roles of $\mathrm{N}$-acetylglutaminylglutamine amide and glycine betaine in adaptation of Pseudomonas aeruginosa to osmotic stress. Appl Environ Microbiol 59, 473-478

Eisenberg RC, Butters SJ, Quay SC, Friedman SB (1974) Glucose uptake and phosphorylation in Pseudomonas fluorescens. J Bacteriol 120, 147-153

Engesser KH, Schule P (1989) Degradation of 2bromo-, 2-chloro- and 2-fluorobenzoate by Pseudomonas putida CLB250. FEMS Microbiol Lett 60, 143-147 
Entner N, Doudoroff M (1952) Glucose and gluconic oxidation of Pseudomonas saccharophila. J Biol Chem 196, 853-862

Frey P, Frey-Klett P, Garbaye J, Berge O, Heulin T (1997) Metabolic and genotypic fingerprinting of fluorescent pseudomonads associated with the Douglas Fir-Laccaria bicolor mycorrhizosphere. Appl Environ Microbiol 63, 1852-1860

Fothergill JC, Guest JR (1977) Catabolism of L-lysine by Pseudomonas aeruginosa. J Gen Microbiol 99, 139-155

Gamble TN, Betlach MR, Tiedje JM (1977) Numerically dominant denitrifying bacteria from world soils. Appl Environ Microbiol 33, 926-939

Golovleva LA, Maltseva OV, Solyanikova IP (1992) Metabolism of foreign compounds in Pseudomonas spp (1992) In : Pseudomonas, Molecular Biology and Biotechnology (E Galli, S Silver, B Witholt, eds), Am Soc Microbiol, Washington, DC, 231-238

Gottschalk G (1979a) Catabolic activities of aerobic heterotrophs. I. Degradation of polymers by exoenzymes. In : Bacterial Metabolism (MP Starr, ed), Springer-Verlag, New York, 114-116

Gottschalk G (1979b) Catabolic activities of aerobic heterotrophs. III. Growth with organic acids. In : Bacterial Metabolism (MP Starr, ed), SpringerVerlag, New York, 118-123

Grimont PAD, Vancanneyt $\mathbf{M}$, Lefèvre $\mathbf{M}$, Vandemeulebroecke K, Vauterin L, Brosh R, Kersters K, Grimont F (1996) Ability of biolog and biotype-100 systems to reveal the taxonomic diversity of the pseudomonads. System Appl Microbiol $19,510-527$

Haas D, Galimand M, Gamper M, Zimmermann A (1990) Arginine network of Pseudomonas aeruginosa: Specific and global controls. In : Pseudomonas Biotransformations, Pathogenesis, and Evolving Biotechnology (S Silver, AM Chakrabarty, B Iglewski, S Kaplan, eds), Am Soc Microbiol, Washington, DC, 303-313

Haas D, Keel C, Laville J, Maurhofer M, Oberhänsli T, Schnider U, Voisard C, Wüthrich B, Défago G (1991) Secondary metabolites of Pseudomonas fluorescens strain $\mathrm{CHA} 0$ involved in the suppression of root diseases. In : Advances in Molecular Genetics of Plant-Microbe Interactions (H Hennecke, DPS Verma, eds), Kluwer Academic Publishers, Dordrecht, 1, 450-456

Harayama S, Wasserfallen A, Cerdan P, Rekik M (1992) Mutational modification of the substrate specificity of catechol 2,3-dioxygenase encoded by TOL plasmid pWW0 of Pseudomonas putida. In : Pseudomonas, Molecular Biology and Biotechnology (E Galli, S Silver, B Witholt, eds), Am Soc Microbiol, Washington, DC, 223-230

Harwood CS, Rivelli M, Ornston LN (1984) Aromatic acids are chemoattractants for Pseudomonas putida. $J$ Bacteriol 160, 622-628
Hojberg O, Sorensen J (1993) Microgradients of microbial oxygen consumption in a barley rhizosphere model system. Appl Environ Microbiol 59, 431-437

Holloway BW (1992) Pseudomonas in the late twentieth century. In : Pseudomonas, Molecular Biology and Biotechnology (E Galli, S Silver, B Witholt, eds), Am Soc Microbiol, Washington, DC, 1-8

Hug DH, Roth D, Hunter J (1968) Regulation of histidine catabolism by succinate in Pseudomonas putida. J Bacteriol 96, 396-402

Hunt JC, Phibbs JR (1983) Regulation of alternate peripheral pathways of glucose catabolism during aerobic and anaerobic growth of Pseudomonas aeruginosa. J Bacteriol 154, 793-802

Jacques MA (1994) Écologie quantitative et physiologie de la communauté bactérienne épiphylle de Cichorium endivia var latifolia $\mathrm{L}$. Thèse de doctorat, université de Paris-XI, Orsay, 123 p

Knowles R (1982) Denitrification. Microbiol Rev 46, 43-70

Knowles CJ, Bunch AW (1986) Microbial cyanide metabolism. Adv Microb Physiol 27, 73-111

Kornberg HL (1958) The metabolism of $\mathrm{C}_{2}$ compounds in microorganisms. 1. The incorporation of ${ }^{2-14} \mathrm{C}$ acetate by Pseudomonas fluorescens, and by a Corynebacterium, grown on ammonium acetate. Biochem J 68, 535-541

Kornberg HL, Madsen NB (1958) The metabolism of $\mathrm{C} 2$ compounds in microorganisms. 3. Synthesis of malate from acetate via the glyoxylate cycle. Biochem J 68, 549-557

Lam ST, Torkewitz NR, Nautiyal CS, Dion P (1991) Impact of the ability to utilize a single substrate on colonization competitiveness. Phytopathology 81, 1163-1164

Latour X (1996) Effet de la plante et du sol sur la diversité des populations telluriques de Pseudomonas spp fluorescents. Thèse de doctorat, université de Bourgogne, $70 \mathrm{p}$

Latour X, Corberand T, Laguerre G, Allard F, Lemanceau P (1996) The composition of fluorescent pseudomonad populations associated with roots is influenced by plant and soil type. Appl Environ Microbiol 62, 2449-2456

Lemanceau P (1992) Effets bénéfiques de rhizobactéries sur les plantes : exemple des Pseudomonas spp fluorescens. agronomie 12, 413-437

Lemanceau P, Alabouvette C (1993) Suppression of fusarium wilts by fluorescent pseudomonads: mechanisms and applications. Biocontrol Sci Technol 3, 219-234

Lemanceau P, Corberand T, Gardan L, Latour X, Laguerre G, Bœufgras JM, Alabouvette C (1995) Effect of two plant species (Linum usitatissinum L., Lycopersicon esculentum Mill.) on the diversity of soil populations of fluorescent pseudomonads. Appl Environ Microbiol 61, 1004-1012 
Lessie TG, Phibbs PV Jr (1984) Alternative pathways on carbohydrate utilization in Pseudomonads. Annu Rev Microbiol 38, 359-387

Lewis KF, Blumenthal HJ, Weinrack RS, Weinhouse S (1955) An isotope tracer study of glucose catabolism in Pseudomonas fluorescens. J Biol Chem 216, 273278

Lucas P, Sarniguet A, Collet JM, Lucas M (1989) Réceptivité des sols au piétin-échaudage (Gaeumannomyces graminis var. tritici) : influence de certaines techniques culturales. Soil Biol Biochem 21, 1073-1078

McGregor CH, Wolff JA, Arora SK, Hylemon PB, Phibbs PV (1992) Catabolite repression control in Pseudomonas aeruginosa. In : Pseudomonas, Molecular Biology and Biotechnology (E Galli, S Silver, B Witholt, eds), Am Soc Microbiol, Washington, DC, 198-207

Marshall VD, Sokatch JR (1972) Regulation of valine catabolism in Pseudomonas putida. J Bacteriol 110, 1073-1081

Martin RR, Marshall VD, Sokatch JR, Unger L (1973) Common enzymes of branched-chain amino acid catabolism in Pseudomonas putida. J Bacteriol 115 , 198-204

Martinez-Blanco H, Reglero A, Rodriguez-Aparicio LB, Luengo JM (1990) Purification and biochemical characterization of phenylacetyl-CoA ligase from Pseudomonas putida. A specific enzyme for the catabolism of phenylacetic acid. J Biol Chem 265, 7084-7090

Matsubara T, Zumft WG (1982) Identification of a copper protein as part of the nitrous oxide-reducing system in nitrite-respiring (denitrifying) pseudomonads. Arch Microbiol 132, 322-328

Maurhofer M, Keel C, Schnider U, Voisard C, Haas D, Défago $G$ (1992) Influence of enhanced antibiotic production in Pseudomonas fluorescens strains CHAO on its disease suppressive capacity. Phytopathology 82, 190-195

Mercenier A, Simon JP, Vander Wauven C, Haas D, Stalon V (1980) Regulation of enzyme synthesis in the arginine deiminase pathway of Pseudomonas aeruginosa. J Bacteriol 144, 159-163

Miller DL, Rodwell VW (1971) Metabolism of basic amino acids in Pseudomonas putida. J Biol Chem 246, 2758-2764

Miller KJ, Wood JM (1996) Osmoadaptation by rhizosphere bacteria. Annu Rev Microbiol 50, 101-136

Misaghi I, Grogan RG (1969) Nutritional and biochemical comparisons of plant-pathogenic and saprophytic fluorescent pseudomonads. Phytopathology $59,1436-1450$

Müller J, Boller T, Wieken A (1995) Trehalose and trehalase in plants: recent developments. Plant Sci 112, $1-9$

Newell CP, Lessie TG (1970) Induction of histidinedegrading enzymes in Pseudomonas aeruginosa. $J$ Bacteriol 104, 596-598
Numa S, Ishimura Y, Nakazawa D, Okazaki T, Hayaishi O (1964) Enzymatic studies on the metabolism of glutarate in Pseudomonas. $J$ Biol Chem 239, 3915-3922

Ornston LN (1971) Regulation of catabolic pathways in Pseudomonas. Bacteriol Rev 35, 87-116

Palleroni NJ (1984) Gram-negative aerobic rods and cocci: family I Pseudomonadaceae. In : Bergey's Manual of Bacteriology (NR Krieg, JG Holt, eds), William \& Wilkins, Baltimore, 1, 141-199

Palleroni NJ (1992). Introduction to the family Pseudomonadaceae. In : The Prokaryotes (MP Balows, ed), Springer-Verlag, New York, 30713085

Palleroni NJ, Doudoroff M (1956) Mannose isomerase of Pseudomonas saccharophila. J Biol Chem 218, 535-548

Phillips AT, Mulfinger LM (1981) Cyclic adenosine 3',5'-monophophate levels in Pseudomonas putida and Pseudomonas aeruginosa during induction and carbon catabolite repression of histidase synthesis. $J$ Bacteriol 145, 1286-1292

Pierson III LS, Wood DW (1994) A diffusible signal molecule regulates phenazine expression in Pseudomonas aureofaciens. Phytopathology 84, 1082

Pierson III LS, Keppenne VD, Wood DW (1994) Phenazine antibiotic biosynthesis in Pseudomonas aureofaciens $30-84$ is regulated by $P h z R$ in response to cell density. J Bacteriol 176, 3966-3974

Quay SC, Friedman SB, Eisenberg RC (1972) Gluconate regulation of glucose catabolism in Pseudomonas fluorescens. J Bacteriol 112, 291-298

Rayney PB, Bayley MJ, Thompson IP (1994) Phenotypic and genotypic diversity of fluorescent pseudomonads isolated from field-grown sugar beet. Microbiology 140, 2315-2331

Roehl RA, Phibbs PV (1982) Characterization and genetic mapping of fructose phosphotransferase mutations in Pseudomonas aeruginosa. J Bacteriol $149,897-905$

Sands DC, Gleason FH, Hildebrand DC (1967) Cytochromes of Pseudomonas syringae. J Bacteriol 94, 1785-1786

Sawyer MH, Baumann P, Baumann L, Berman SM, Canovas JL (1977) Pathways of D-fructose catabolism in species of Pseudomonas. Arch Microbiol $112,49-55$

Schleissner C, Reglero A, Luengo JM (1997) Catabolism of D-glucose by Pseudomonas putida $\mathrm{U}$ occurs via extracellular transformation into D-gluconic acid and induction of a specific gluconate transport system. Microbiology 143, 1595-1603

Schleissner C, Olivera ER, Fernandez-Valverde M, Luengo JM (1994) Aerobic catabolism of phenylacetic acid in Pseudomonas putida U: biochemical characterization of a specific phenylacetic acid transport system and formal demonstration that phe- 
nylacetyl-Coenzyme A is a catabolic intermediaite. $J$ Bacteriol 176, 7667-7676

Schroth MN, Hildebrand DC, Panopoulos N (1992) Phytopathogenic pseudomonads and related plantassociated pseudomonads,. In : The Prokaryotes (MP Balows, ed), Springer-Verlag, New York, 3104-3131

Schweizer HP, Po C (1996) Regulation of glycerol metabolism in Pseudomonas aeruginosa: characterization of the glpR repressor gene. J Bacteriol 178 , 5215-5221

Sebek OK, Randles CI (1952) the oxidative dissimilation of mannitol and sorbitol by Pseudomonas fluorescens. J Bacteriol 63, 693-695

Shanahan P, O'Sullivan DJ, Simpson P, Glennon JD, O'Gara F (1992) Isolation of 2,4-diacetylphloroglucinol from a fluorescent pseudomonad and investigation of physiological parameters influencing its production. Appl Environ Microbiol 58, 353-358

Shoesmith JG, Sherris JC (1960) Studies on the mechanism of arginine-activated motility in a Pseudomonas strain. J Gen Microbiol 22, 10-24

Siegel LS, Phibbs PV (1979) Glycerol and L-(-glycerol-3-phosphate uptake by Pseudomonas aeruginosa. Curr Microbiol 2, 251-256

Smith M, Tiedje JM (1979) The effect of roots on soil denitrification. Soil Sci Soc Am J 43, 951-955

Stalon V, Mercenier A (1984) L-Arginine utilization by Pseudomonas species. J Gen Microbiol 130, 69-76

Stalon V, Ramos F, Pierard D, Wiame JM (1972) Regulation of the catabolic ornithine carbamoyletransferase in Pseudomonas fluorescens: a comparaison with the anabolic transferase and with a mutationally modified catabolic transferase. Eur $J$ Biochem 29, 25-35

Stalon V, Vander Wauven C, Momin P, Legrain C (1987) Catabolism of arginine, citrulline and ornithine by Pseudomonas and related bacteria. J Gen Microbiol 133, 2487-2495

Stanier RY, Ornston LN (1973) Aromatic compounds that can be converted to catechol. Adv Microbial Physiol 9, 89-151

Stanier RY, Palleroni NJ, Doudoroff M (1966) The aerobic pseudomonads, a taxonomic study. J Gen Microbiol 43, 159-271

Stephens PM, Crowley JJ, O'Connell C (1993) Selection of pseudomonad strains inhibiting Pythium ultimum on sugarbeet seeds in soil. Soil Biol Biochem 9, 1283-1288

Styrvold OB, Strom AR (1991) Synthesis, accumulation, and excretion of trehalose in osmotically stressed Escherichia coli K-12 strains: influence of amber suppressors and function of the periplasmic trehalase. J Bacteriol 173, 1187-1192
Thomashow LS (1991) Molecular basis of antibiosis mediated by rhizosphere pseudomonads. In : Plant Growth-Promoting Rhizobacteria, Progress and Prospects (C Keel, B Koller, G Défago, eds), IOBC/WPRS, XIV/8, 109-115

Thöny-Meyer L (1997) Biogenesis of respiratory cytochromes in bacteria. Microbiol Mol Biol Rev 61, $337-376$

Thornley MJ (1960) The differentiation of Pseudomonas from other gram-negative bacteria on the basis of arginine metabolism. J Appl Bacteriol $23,37-52$

Tiedje JM (1988) Ecology of denitrification and dissimilatory nitrite reduction to ammonium. In : Biology of Anaerobic Microorganisms (AJB Zehnder, ed), Wiley Interscience Publications, New York, 179244

Vancura V (1988) Plant metabolites in soil. In : Soil Microbial Association (V Vancura, V Kunc, eds), Elsevier, Amsterdam, 57-132

Van Laere A (1989) Trehalose, reserve and/or stress metabolite? FEMS Microbiol Rev 63, 201-210

Voisard C, Bull C, Keel C, Laville J, Maurhofer M, Schnider U, Défago G, Haas D (1994) Biocontrol of root diseases by Pseudomonas fluorescens CHA0: current concepts and experimental approaches. In : Molecular Ecology of Rhizosphere Microorganisms (F O'Gara, D Dowling, B Boesten, eds), VCH, Weinheim, 67-89

Weller DM, Thomashow LS (1993) Microbial metabolites with biological activity against plant pathogens. In : Pest Management: Biologically Based Technologies (RD Lumsden, JL Vaughn, eds), Am Chem Soc, Washington, DC, 67-89

Whiting PH, Midgley M, Dawes EA (1976) The role of glucose limitation in the regulation of the transport of glucose, gluconate and 2-oxogluconate, and of glucose catabolism, in Pseudomonas aeruginosa. $J$ Gen Microbiol 92, 304-310

Wolfe JB, Ivler D, Rittenberg SC (1954) Malonate decarboxylation by Pseudomonas fluorescens. I. Observations with dry cells and cell-free extracts. $J$ Biol Chem 209, 867-874

Wolfe JB, Ivler D, Rittenberg SC (1954) Malonate decarboxylation by Pseudomonas fluorescens. II. $\mathrm{Mg}^{2+}$ dependency and trapping of active intermediates. I Biol Chem 209, 875-884

Wolfe JB, Ivler D, Rittenberg SC (1954) Malonate decarboxylation by Pseudomonas fluorescens. III. Role of acetylCoA. J Biol Chem 209, 885-895

Wood WA (1955) Pathways of carbohydrate degradation in Pseudomonas fluorescens. Bacteriol Rev 19, 222-233 